\title{
What neighborhood area captures built environment features related to adolescent physical activity?
}

\author{
Janne Boone-Heinonen ${ }^{a}$, Penny Gordon-Larsen ${ }^{a}$, Barry M. Popkin ${ }^{a}$, and Yan Song ${ }^{b}$ \\ a Department of Nutrition, Gillings School of Global Public Health, University of North Carolina at \\ Chapel Hill, 123 West Franklin St., CB\#8120, Chapel Hill, NC 27516-3997 \\ $\mathrm{b}$ Department of City and Regional Planning, College of Arts and Sciences, University of North \\ Carolina at Chapel Hill, UNC-CH New East Building, CB\#3140, Chapel Hill, NC 27599-3140
}

\begin{abstract}
In research investigating built environment (BE) influences on physical activity (PA), inconsistent neighborhood definitions may contribute to inconsistent findings. Using data from the National Longitudinal Study of Adolescent Health (Wave I; 1994-95), we compared associations between moderate-vigorous PA (MVPA) and PA facility counts and street connectivity measures (intersection density and link:node ratio) within $1,3,5$, and 8.05 kilometers $(\mathrm{km})$ from each respondent's residence (Euclidean neighborhood buffers). BE-MVPA associations varied by BE characteristic, urbanicity, and sex. PA facilities within $3 \mathrm{~km}$ buffers and intersection density within $1 \mathrm{k}$ buffers exhibited the most consistent associations with MVPA. Policy recommendations and corresponding research should address potential differences in relevant neighborhood areas across environment feature and population subgroup.
\end{abstract}

\section{Keywords $\left(\mathrm{MeSH}^{\star}\right)$}

Environment design*; physical activity*; adolescent*; epidemiology*; modifiable areal unit problem; neighborhood definition; United States

\section{INTRODUCTION}

\begin{abstract}
Despite some evidence that built environment (BE) features (e.g., recreation facilities, street connectivity) may promote physical activity (PA), associations vary dramatically across studies (Saelens and Handy, 2008, Wendel-Vos et al., 2007). Inconsistent study findings could result, in part, from variation in neighborhood definitions, which may capture neighborhood features relevant to PA to varying degrees, depending on the type of BE feature and population subgroup (Colabianchi et al., 2007, Diez Roux, 2007, Soobader et al., 2006).
\end{abstract}

(C) 2010 Elsevier Ltd. All rights reserved.

*Please Address Correspondence \& Reprint Requests To: Penny Gordon-Larsen, Ph.D. University of North Carolina at Chapel Hill Carolina Population Center University Square 123 West Franklin St. Chapel Hill, NC 27516-3997 Phone: (W) 919-843-9966; (H) 919-968-6594; Fax: 919-966-9159 gordon_larsen@unc.edu.

Publisher's Disclaimer: This is a PDF file of an unedited manuscript that has been accepted for publication. As a service to our customers we are providing this early version of the manuscript. The manuscript will undergo copyediting, typesetting, and review of the resulting proof before it is published in its final citable form. Please note that during the production process errors may be discovered which could affect the content, and all legal disclaimers that apply to the journal pertain. 
Findings from the few empirical comparisons of objectively defined neighborhoods are mixed, showing dramatic (Zhang and Kukadia, 2005) or inconsequential (Lovasi et al., 2008, Berke et al., 2007, Diez Roux et al., 2007, Forsyth et al., 2008) differences in associations according to neighborhood size. However, these studies focus on adult, generally metropolitan samples and lack the size and diversity needed to evaluate subgroup differences.

Our objective was to determine the most salient circular neighborhood area for capturing BE features (PA facilities and street connectivity) most strongly associated with moderatevigorous PA (MVPA) in a nationally representative sample of adolescents. We considered areas within 1, 3, 5, and 8.05 kilometers $(\mathrm{km})$ of each respondents' home (Euclidian neighborhood buffers) using a unique database which provided exceptional geographic variability.

\section{METHODS}

\section{Study population and data sources}

We used Wave I data ( $\mathrm{n}=20,745 ; 11-22$ years of age) from The National Longitudinal Study of Adolescent Health (Add Health), a prospective cohort study of adolescents representative of the U.S. school-based population in grades 7 to 12 in 1994-95. The survey design and sampling frame have been discussed elsewhere (Resnick et al., 1997).

Using complex Geographic Information System (GIS) techniques, we linked time-varying, community-level data to Add Health respondent residential locations determined from (of 18,924 adolescents in the probability sample) geocoded home addresses with street-segment matches $(n=15,480)$, global positioning system (GPS) measurements $(n=2,996), Z I P / Z I P+4 /$ $Z I P+2$ centroid match $(n=205)$, and respondent's geocoded school location $(n=243)$ (BooneHeinonen et al., 2010). Results were virtually identical after excluding respondents with ZIP- or school location-imputed locations. Attributes of the circular area within 1, 3, 5, and $8.05 \mathrm{~km}(8.05 \mathrm{~km}=5$ miles$)$ of each respondent residence and block group, tract, and county from U.S. Census and other federal sources were merged with individual-level Add Health interview responses.

The final sample included 17,659 adolescents for analysis. Exclusions included self-reported pregnancy $(\mathrm{n}=401)$ or mobility disability $(\mathrm{n}=122)$ and Native Americans due to sparse data $(\mathrm{n}=156)$; of the remaining sample, those with missing analytic variables were also excluded $(\mathrm{n}=589)$.

\section{Study variables}

GIS-derived BE characteristics of interest (1, 3, 5, and $8.05 \mathrm{~km}$ buffers)-PA facility counts were obtained from a historical dataset of U.S. businesses (1995) with high overall agreement between commercial and field data (Boone et al., 2008) and classified according to 8-digit Standard Industrial Classification codes. We also examined facility counts weighted by the inverse distance from each respondent (facilities between 1 and 8 $\mathrm{km}$ ); facilities within $1 \mathrm{~km}$ received weights of 1 .

Two measures of street connectivity, an indicator of the number and directness of route options (Saelens et al., 2003), were calculated from the ESRI StreetMap 2000 dataset. Link:node ratio represents the number of links (street segments) relative to the number of nodes (intersections); intersection density is the number of 3 or more-way intersections per square $\mathrm{km}$. Higher values indicate higher connectivity. 
GIS-derived control variables-U.S. Census-defined urbanized areas (UA) were used to classify residential locations as non-urban or urban. Urban locations were further categorized into "low-urban" and "high-urban" based on the area of developed land as a proportion of total area within $8 \mathrm{~km}$ after excluding water and ice $\left[\leq\right.$ or $>78 \%\left(75^{\text {th }}\right.$ percentile) developed landcover, respectively], calculated using Fragstats software (McGarigal et al., 2002) with U.S. Geologic Survey National Landcover Data (1992). This measure provided an indicator of urban development that is independent of population density and correctly classifies areas as within or outside of a UA (Receiver Operating Curve area $=0.986$ ).

Analyses controlled for percent of persons below poverty within census tracts. 1990 Census population counts weighted according to the proportion of the block-group area captured within the buffer were divided by the buffer area to obtain population density within each buffer. Population density was used to control for density-related characteristics and per capita availability of facilities. County-level non-violent and violent crime rate per 100,000 population was obtained from 1995 Uniform Crime Reporting data.

Self-reported behaviors and sociodemographics-Weekly frequency (bouts) of MVPA (skating \& cycling, exercise, and active sports) was ascertained using a standard, interview administered activity recall based on questionnaires validated in other large-scale epidemiologic studies. Individual-level control variables included age at Wave I interview, self-identified race (white, black, Asian, Hispanic); parent-reported annual household income and highest level of education (<high school, high school or GED, some college, $\geq$ college degree), and administratively determined U.S. region (West, Midwest, South, and Northeast).

\section{Statistical analysis}

Sample characteristics-We compared neighborhood-level characteristics across three levels of urbanicity and individual-level characteristics across sex and urbanicity using design-based F-tests and Wald tests for categorical and continuous characteristics, respectively, with Bonferroni correction for multiple comparisons. Descriptive analyses were weighted for national representation and adjusted for multiple stages of cluster sampling.

Multivariable analysis-Using negative binomial regression models, we examined the number of weekly MVPA bouts as a function of PA facilities count, intersection density, or link:node ratio within 1, 3, 5, or 8.05 Euclidean buffers. All models adjusted for individuallevel (continuous age, race, household income tertile, highest parental education, region) and neighborhood-level (poverty and crime tertiles; urbanicity-specific population density tertile) covariates. Due to potential identification error (Oakes, 2004) posed by dramatic variation in $\mathrm{BE}$ measures across urbanicity, we stratified by urbanicity rather than testing for urbanicity interactions. We included statistically significant $(\mathrm{p}<0.10)$ sex-BE interactions.

Subsequently, we fit an analogous model with the most salient measures from the first set of models (PA facilities counts within $3 \mathrm{~km}$ and intersection density within $1 \mathrm{~km}$ ); this model adjusted for population density within $1 \mathrm{~km}$, but adjusting for population density within 3 $\mathrm{km}$ yielded similar estimates.

All models adjusted for clustering on our primary sampling unit (schools). Given that schools are not nested within census tracts and counties, we did not use multi-level analysis. Further, intraclass correlations for $\ln (\mathrm{MVPA})$ were minimal (0.03; ICC's are not definable for negative binomial distributed outcomes), and multi-level analysis of unbalanced, sparse 
data (mean $=8$, range $=1-275$ respondents per census tract) within geographic units can result in biased estimates (Clarke, 2008).

To address non-linear relationships with MVPA, each model included statistically significant (Wald $\mathrm{p}<0.10$ ) quadratic and cubic terms and, for PA facility counts, analyzed natural-log transformed variables (plus 1 to address zero counts). To stabilize estimates, extreme observations $\left(<0.5^{\text {th }}\right.$ or $>99.5^{\text {th }}$ urbanicity-specific percentile) were dropped if their exclusion simplified the model (e.g., higher order term was no longer significant) or resulted in $>10 \%$ change in the BE coefficient(s); in each model, no more than $1 \%$ of the sample was excluded.

We present exponentiated estimates comparing urbanicity-specific $90^{\text {th }}$ and $10^{\text {th }}$ percentiles (Diez-Roux et al., 1997) for the BE measure of interest, which reflect the proportional difference in MVPA bouts (e.g, 1.05 represents 5\% greater MVPA bouts associated with the $90^{\text {th }}$ versus $10^{\text {th }}$ percentile of a given BE measure). Model coefficients are reported in the Appendix (Table A1).

\section{RESULTS}

In general, we observed dramatic differences in most environmental characteristics among urbanicity levels (Table 1). Individual-level characteristics by sex and urbanicity are presented in the Appendix (Table A2).

The association between MVPA and facility count varied by buffer size and urbanicity (Table 2). The strongest associations were generally observed for $1-5 \mathrm{~km}$ buffers, most consistently for the $3 \mathrm{~km}$ buffer. Associations were strongest in the non- and low-urban strata and were similar by sex. Associations with weighted counts were similar to counts within $1-5 \mathrm{~km}$. Intersection density within $1 \mathrm{~km}$ yielded the strongest associations; in several cases, associations were stronger in males, with the strongest association in high-urban males. Associations between link:node ratio and MVPA were generally positive in nonurban females and negative in high-urban females but otherwise not significant.

After including facilities count within $3 \mathrm{k}$ and intersection density within $1 \mathrm{~km}$ in the same models (Table 3), associations were similar to Table 2 except the MVPA-resource count association was no longer apparent in the non-urban stratum.

\section{DISCUSSION}

In our large, national sample of U.S. adolescents, we found particular relevance for PA facilities within a $3 \mathrm{~km}$ buffer and street connectivity within a $1 \mathrm{~km}$ buffer. Our joint model suggests that MVPA is independently associated with intersection density and, in low-urban adolescents, resource count. Our findings are consistent with prior work (Zhang and Kukadia, 2005) suggesting that behavior is influenced by different features within different neighborhood areas. That is, the relevant neighborhood area may be larger for PA facilities (due to higher incentive to travel) than for intersection density (which may encourage streetbased activities such as skateboarding or jogging closer to home (Nelson et al., 2005)).

Observed variation in BE-MVPA associations by buffer size, type of BE characteristic, sex, and urbanicity could produce inconsistent BE-PA associations in existing research. Our link:node ratio findings suggest that while high street connectivity might encourage walking in adults (Ewing et al., 2003, Doyle et al., 2006, Frank et al., 2004), dead end streets or cul de sacs might encourage street-based PA in high-urban, adolescent females. This finding also suggests that our two street connectivity measures appear to capture different characteristics. More consistent BE-MVPA associations in males versus females could 
reflect the stronger role of safety concerns (Roman and Chalfin, 2008) and sociodemographic characteristics (Frank et al., 2008) in females or higher male participation in organized PA (Vilhjalmsson and Kristjansdottir, 2003), which is more easily measured. Finally, while most studies, even those with national samples (Boer et al., 2007, Powell et al., 2007, Ewing et al., 2003), ignore urbanicity, we found urbanicity differences which may reflect differences in effect, omission of safety or complex social or physical factors represented by urbanicity (Vlahov and Galea, 2002), or dramatic differences in the range of BE measures captured across urbanicity.

Our study has several limitations. First, cross-sectional associations do not imply causality (Boone-Heinonen et al., 2009). Second, optimal buffer size may vary by type of PA facility and type of PA (Giles-Corti et al., 2005); however, our total leisure-time MVPA measure is a tradeoff for the size and scope of the Add Health study, and results were similar after excluding active sports, which may be performed farther from home. Third, we did not consider quality of facilities or moderation by perceived or objective safety. Fourth, selection bias (Hernan et al., 2004) resulting from urbanicity stratification is possible, as selection of non-, low-, or high-urban areas may be related to both neighborhood amenities and propensity for PA. Fifth, while we did not examine alternative neighborhood definitions such as buffers based on street network distances, administrative areas (e.g., census tracts), or other methods (Chaix et al., 2009), our comparison of circular buffers enabled explicit comparisons of various neighborhood sizes. Finally, while empirically comparing neighborhood definitions has limitations (Spielman and Yoo, 2009), our study contributes by estimating effects of objectively measured neighborhood characteristics within various areas for a geographically diverse, nationally representative sample population.

\section{Conclusion and implications}

In our cross-sectional study, higher MVPA was generally associated with resource counts and intersection density within $1-5 \mathrm{~km}$ and $1 \mathrm{~km}$ of respondents' homes, respectively. These findings suggest that recommendations should specify the relevant scale and setting. For example, guidelines for minimum intersection density based on research within a $1 \mathrm{~km}$ buffer in high-urban areas applied to larger scales or in suburban areas may not be valid. Until consensus on the most relevant scale is reached, reporting of associations within various neighborhood sizes is recommended. More research in diverse geographic areas which include currently understudied rural and suburban areas, as well as further examination of age and sex differences is needed.

\section{Acknowledgments}

The authors would like to thank Brian Frizzelle, Marc Peterson, Chris Mankoff, James D. Stewart, Phil Bardsley, and Diane Kaczor of the University of North Carolina, Carolina Population Center (CPC) and the CPC Spatial Analysis Unit for creation of the environmental variables and Jillian H Jefferson for her assistance with our literature review of existing buffer measures. The authors also thank Ms. Frances Dancy for her helpful administrative assistance. There were no potential or real conflicts of financial or personal interest with the financial sponsors of the scientific project.

\footnotetext{
This work was funded by National Institutes of Health grants R01HD057194 and R01 HD041375, R01 HD39183, and a cooperative agreement with the Centers for Disease Control and Prevention (CDC SIP No. 5-00), dissertation grants from the Robert Wood Johnson Foundation's Active Living Research and Centers for Disease Control and Prevention (R36-EH000380), and The Henry Dearman and Martha Stucker Dissertation Fellowship in the Royster Society of Fellows at the University of North Carolina at Chapel Hill. Funding sources had no role in the study design, collection, analysis, or interpretation of data, the writing of the report, or the decision to submit the paper for publication.
}

This research uses data from Add Health, a program project designed by J. Richard Udry, Peter S. Bearman, and Kathleen Mullan Harris, and funded by a grant P01-HD31921 from the Eunice Kennedy Shriver National Institute of Child Health and Human Development, with cooperative funding from 17 other agencies. Special 
acknowledgment is due Ronald R. Rindfuss and Barbara Entwisle for assistance in the original design. Persons interested in obtaining data files from Add Health should contact Add Health, CPC, 123 W. Franklin Street, Chapel Hill, NC 27516-2524 (addhealth@unc.edu). No direct support was received from grant P01-HD31921 for this analysis.

\section{APPENDIX}

\section{Table A1}

Regression coefficients ${ }^{a}$ for MVPA modeled as a function of $\ln$ (resource counts), intersection density and link:node ratio within 1,3,5, and 8.05k circular buffer, by urbanicity ${ }^{b}$ level

\begin{tabular}{|c|c|c|c|c|c|c|c|c|c|c|}
\hline & & \multicolumn{3}{|c|}{ Resources } & \multicolumn{3}{|c|}{ Intersection Density } & \multicolumn{3}{|c|}{ Link:Node Ratio } \\
\hline & & coeff & sig & $\mathrm{n}$, exclusions $c$ & coeff & sig & $\begin{array}{c}\mathrm{n}, \\
\text { exclusions }\end{array}$ & coeff & sig & $\mathrm{n}$, exclusions ${ }^{c}$ \\
\hline \multicolumn{11}{|l|}{$\frac{\text { Non-Urban }}{(\mathrm{n}=6889)}$} \\
\hline \multirow[t]{2}{*}{$1 \mathrm{~km}$} & linear & 0.036 & 0.012 & 6861, hi & 0.054 & 0.005 & 6853, hi & -0.028 & 0.131 & 6882, hi \\
\hline & squared & $--d$ & & & -0.005 & 0.082 & & $--d$ & & \\
\hline \multirow[t]{4}{*}{$3 \mathrm{~km}$} & linear & 0.027 & 0.024 & 6889 & 0.064 & 0.000 & 6855, hi & 2.264 & 0.035 & 6855 , hi \\
\hline & linear*female & $--d$ & & & $--d$ & & & -1.662 & 0.191 & \\
\hline & squared & $--d$ & & & $--d$ & & & -0.803 & 0.029 & \\
\hline & squared $*$ female & $--d$ & & & $--d$ & & & 0.642 & 0.141 & \\
\hline \multirow[t]{4}{*}{$5 \mathrm{~km}$} & linear & 0.021 & 0.098 & 6889 & 0.045 & 0.092 & 6855 , hi & 3.953 & 0.000 & 6889 \\
\hline & linear*female & $--d$ & & & $--d$ & & & -5.127 & 0.000 & \\
\hline & squared & $--d$ & & & $--d$ & & & -1.440 & 0.000 & \\
\hline & squared*female & $--d$ & & & $--d$ & & & 1.936 & 0.000 & \\
\hline \multirow[t]{6}{*}{$8 \mathrm{~km}$} & linear & 0.004 & 0.751 & 6855 , hi & 0.005 & 0.978 & 6825, hi/lo & 3.517 & 0.062 & 6821, hi/lo \\
\hline & linear*female & $--d$ & & & -0.334 & 0.061 & & -7.097 & 0.009 & \\
\hline & squared & $--d$ & & & -0.039 & 0.816 & & -1.270 & 0.060 & \\
\hline & squared $*$ female & $--d$ & & & 0.395 & 0.036 & & 2.678 & 0.006 & \\
\hline & cubed & $--d$ & & & 0.004 & 0.919 & & $-{ }_{-} d$ & & \\
\hline & cubed*female & $--d$ & & & -0.097 & 0.056 & & $--d$ & & \\
\hline weighted & linear & 0.031 & 0.018 & 6889 & -NA- & & & -NA- & & \\
\hline \multicolumn{11}{|l|}{$\frac{\underline{\text { Low-urban }}}{(\mathrm{n}=6450)}$} \\
\hline \multirow[t]{6}{*}{$1 \mathrm{~km}$} & linear & 0.022 & 0.025 & 6450 & -0.053 & 0.127 & 6418, hi & 0.073 & 0.257 & 6388, hi/lo \\
\hline & linear*female & $--d$ & & & -0.003 & 0.958 & & $-{ }_{--}^{d}$ & & \\
\hline & squared & $--d$ & & & 0.014 & 0.034 & & $--d$ & & \\
\hline & squared $*$ female & $--d$ & & & -0.007 & 0.564 & & $--d$ & & \\
\hline & cubed & $--d$ & & & -0.001 & 0.039 & & $--d$ & & \\
\hline & cubed*female & $--d$ & & & 0.001 & 0.436 & & $--d$ & & \\
\hline \multirow[t]{2}{*}{$3 \mathrm{~km}$} & linear & 0.020 & 0.016 & 6450 & 0.002 & 0.813 & 6418 & 0.139 & 0.095 & 6450 \\
\hline & linear*female & $--d$ & & & -0.022 & 0.038 & & $--d$ & & \\
\hline \multirow[t]{2}{*}{$5 \mathrm{~km}$} & linear & -0.112 & 0.020 & 6433, lo & -0.001 & 0.964 & 6387, hi/lo & 0.175 & 0.121 & 6450 \\
\hline & squared & 0.024 & 0.002 & & $--d$ & & & $-{ }_{--} d$ & & \\
\hline \multirow[t]{2}{*}{$8 \mathrm{~km}$} & linear & -0.228 & 0.006 & 6382, hi/lo & -0.135 & 0.009 & 6450 & 0.101 & 0.438 & 6417, hi \\
\hline & linear*female & $--d$ & & & 0.130 & 0.030 & & $-{ }_{--} d$ & & \\
\hline
\end{tabular}

Health Place. Author manuscript; available in PMC 2011 November 1. 


\begin{tabular}{|c|c|c|c|c|c|c|c|c|c|c|}
\hline & & \multicolumn{3}{|c|}{ Resources } & \multicolumn{3}{|c|}{ Intersection Density } & \multicolumn{3}{|c|}{ Link:Node Ratio } \\
\hline & & coeff & sig & $\mathrm{n}$, exclusions $c$ & coeff & sig & $\underset{\text { exclusions }}{\mathrm{n}} \boldsymbol{c}$ & coeff & sig & $\mathbf{n}$, exclusions ${ }^{c}$ \\
\hline \multirow{4}{*}{ weighted } & squared & 0.030 & 0.001 & & 0.030 & 0.003 & & $-d$ & & \\
\hline & squared*female & $--d$ & & & -0.031 & 0.016 & & $--d$ & & \\
\hline & linear & -0.152 & 0.016 & 6385, hi/lo & -NA- & & & -NA- & & \\
\hline & squared & 0.033 & 0.001 & & & & & & & \\
\hline \multicolumn{11}{|l|}{$\frac{\text { High Urban }}{\underline{(\mathrm{n}=4320)}}$} \\
\hline \multirow[t]{5}{*}{$1 \mathrm{~km}$} & linear & -0.154 & 0.007 & 4299, hi & 0.020 & 0.575 & 4277, hi/lo & 13.671 & 0.014 & 4279, hi/lo \\
\hline & linear*female & 0.343 & 0.000 & & 0.078 & 0.157 & & $--d$ & & \\
\hline & squared & 0.045 & 0.024 & & 0.002 & 0.428 & & -8.597 & 0.015 & \\
\hline & squared*female & -0.109 & 0.000 & & -0.011 & 0.029 & & $--d$ & & \\
\hline & cubed & $--d$ & & & $--d$ & & & 1.757 & 0.016 & \\
\hline \multirow[t]{4}{*}{$3 \mathrm{~km}$} & linear & -0.174 & 0.512 & 4307, lo & -0.035 & 0.356 & 4279, hi/lo & -0.021 & 0.905 & 4278, hi/lo \\
\hline & linear*female & 0.831 & 0.031 & & 0.178 & 0.017 & & -0.297 & 0.035 & \\
\hline & squared & 0.024 & 0.451 & & 0.005 & 0.233 & & $--d$ & & \\
\hline & squared*female & -0.115 & 0.022 & & -0.026 & 0.004 & & $--d$ & & \\
\hline \multirow[t]{6}{*}{$5 \mathrm{~km}$} & linear & -0.007 & 0.866 & 4277, hi/lo & -0.128 & 0.040 & 4299, hi & 86.391 & 0.003 & 4300, hi \\
\hline & linear*female & $--d$ & & & 0.450 & 0.002 & & -73.983 & 0.143 & \\
\hline & squared & $--d$ & & & 0.017 & 0.023 & & -56.140 & 0.003 & \\
\hline & squared*female & $--d$ & & & -0.063 & 0.000 & & 46.521 & 0.154 & \\
\hline & cubed & $-{ }_{-}^{d}$ & & & $--d$ & & & 12.082 & 0.002 & \\
\hline & cubed*female & $--d$ & & & $--d$ & & & -9.757 & 0.163 & \\
\hline \multirow[t]{4}{*}{$8 \mathrm{k}$} & linear & -0.026 & 0.589 & 4282, hi/lo & -0.396 & 0.005 & 4278, hi/lo & -0.040 & 0.797 & 4320 \\
\hline & linear*female & $--d$ & & & 0.712 & 0.004 & & -0.557 & 0.026 & \\
\hline & squared & $--d$ & & & 0.055 & 0.003 & & $--d$ & & \\
\hline & squared*female & $--d$ & & & -0.107 & 0.002 & & $--d$ & & \\
\hline weighted & linear & -0.020 & 0.703 & 4278, hi/lo & -NA- & & & -NA- & & \\
\hline
\end{tabular}

${ }^{a}$ Negative binomial regression results modeling MVPA bouts as a function of each built environment measure within each of 4 circular buffers (Euclidean distance). Adjusted for individual-level age and race, household-level income, parental education, census tract-level poverty, county level crime, and population density within corresponding neighborhood buffer size. Each model contains only one built environment variable of interest.

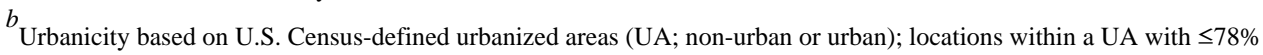
(75th percentile) and $>78 \%$ developed land cover were classified as "low-urban" and "high-urban," respectively.

$c$ hi: observations $>99.5^{\text {th }}$ percentile excluded; lo: observations $<0.5^{\text {th }}$ percentile excluded

$d_{\text {Higher order term not statistically significant }(\mathrm{p}<0.10) \text { and excluded from model MVPA: Moderate to vigorous physical }}$ activity

coeff: coefficient

Table A2

Individual-level characteristics by sex and urbanicity $^{a}$ level [mean /\% (SE)]

\begin{tabular}{lcccccc}
\hline & \multicolumn{3}{c}{ Males } & & \multicolumn{2}{c}{ Females } \\
& $\begin{array}{c}\text { Non-Urban } \\
(\mathbf{n = 3 , 5 0 6 )}\end{array}$ & $\begin{array}{c}\text { Low-Urban } \\
(\mathbf{n = 3 , 1 9 6})\end{array}$ & $\begin{array}{c}\text { High-Urban } \\
(\mathbf{n = 2 , 1 9 2})\end{array}$ & $\begin{array}{c}\text { Non-Urban } \\
(\mathbf{n = 3 , 4 5 3 )}\end{array}$ & $\begin{array}{c}\text { Low-Urban } \\
(\mathbf{n = 3 , 2 5 4})\end{array}$ & $\begin{array}{c}\text { High-Urban } \\
(\mathbf{n = 2 , 1 2 8})\end{array}$ \\
\hline MVPA (mean \# bouts) & $4.1(0.1)$ & $4.1(0.1)$ & $7.4(0.2)$ & $3.4(0.1)$ & $3.3(0.1)$ & $5.2(0.2)$
\end{tabular}

Health Place. Author manuscript; available in PMC 2011 November 1. 


\begin{tabular}{|c|c|c|c|c|c|c|}
\hline & \multicolumn{3}{|c|}{ Males } & \multicolumn{3}{|c|}{ Females } \\
\hline & $\begin{array}{c}\text { Non-Urban } \\
(\mathbf{n}=\mathbf{3 , 5 0 6})\end{array}$ & $\begin{array}{c}\text { Low-Urban } \\
(\mathbf{n}=\mathbf{3 , 1 9 6})\end{array}$ & $\begin{array}{c}\text { High-Urban } \\
(\mathbf{n}=\mathbf{2 , 1 9 2})\end{array}$ & $\begin{array}{c}\text { Non-Urban } \\
(\mathrm{n}=\mathbf{3 , 4 5 3})\end{array}$ & $\begin{array}{c}\text { Low-Urban } \\
(\mathbf{n}=\mathbf{3 , 2 5 4})\end{array}$ & $\begin{array}{c}\text { High-Urban } \\
(\mathbf{n}=\mathbf{2 , 1 2 8})\end{array}$ \\
\hline Age (mean) & $15.4(0.2)$ & $15.5(0.2)$ & $15.7(0.3)$ & $15.2(0.2)$ & $15.3(0.2)$ & $15.5(0.3)$ \\
\hline \multicolumn{7}{|l|}{ Race $^{*}$} \\
\hline white & $80.2(3.7)$ & $70.3(2.8)$ & $21.4(4.0)$ & $80.2(3.8)$ & $70.8(2.8)$ & $24.4(4.9)$ \\
\hline black & $14.8(3.4)$ & $12.7(2.2)$ & $29.0(6.4)$ & $14.7(3.5)$ & $13.7(2.2)$ & $24.9(5.5)$ \\
\hline asian & $1.9(1.2)$ & $4.0(0.9)$ & $10.2(3.5)$ & $1.9(1.1)$ & $3.8(0.8)$ & $9.8(3.9)$ \\
\hline hisp & $3.1(0.8)$ & $13.0(1.7)$ & $39.4(6.7)$ & $3.1(0.8)$ & $11.8(1.5)$ & $41.0(6.8)$ \\
\hline \multicolumn{7}{|l|}{ Education ${ }^{*}$} \\
\hline$<\mathrm{HS}$ & $10.0(1.1)$ & $14.3(1.7)$ & $32.9(4.0)$ & $11.5(1.2)$ & $13.9(1.5)$ & $33.5(4.4)$ \\
\hline HS/GED & $34.6(1.3)$ & $31.8(2.1)$ & $26.6(2.8)$ & $36.4(1.4)$ & $31.6(1.9)$ & $27.9(2.7)$ \\
\hline Some college & $31.5(1.3)$ & $27.0(1.3)$ & $22.9(2.1)$ & $28.9(1.2)$ & $27.4(1.2)$ & $21.0(2.0)$ \\
\hline College or greater & $23.9(1.3)$ & $26.8(3.0)$ & $17.5(2.6)$ & $23.1(1.4)$ & $27.2(3.0)$ & $17.5(3.3)$ \\
\hline \multicolumn{7}{|l|}{ Income Tertile ${ }^{*}$} \\
\hline 1 & $28.6(2.7)$ & $28.7(2.6)$ & $49.2(4.8)$ & $30.9(2.7)$ & $28.9(2.7)$ & $47.2(5.0)$ \\
\hline 2 & $41.6(1.4)$ & $37.2(1.7)$ & $32.8(2.5)$ & $38.8(1.5)$ & $33.3(1.4)$ & $34.1(2.5)$ \\
\hline 3 & $29.8(2.1)$ & $34.1(3.4)$ & $18.0(2.8)$ & $30.2(2.3)$ & $37.8(3.0)$ & $18.7(3.4)$ \\
\hline
\end{tabular}

\section{REFERENCES}

Berke EM, Koepsell TD, Moudon AV, Hoskins RE, Larson EB. Association of the built environment with physical activity and obesity in older persons. Am J Public Health 2007;97:486-92. [PubMed: 17267713]

Boer R, Zheng Y, Overton A, Ridgeway GK, Cohen DA. Neighborhood design and walking trips in ten U.S. metropolitan areas. Am J Prev Med 2007;32:298-304. [PubMed: 17383560]

Boone-Heinonen J, Evenson KR, Song Y, Gordon-Larsen P. Built and socioeconomic environments: patterning and associations with physical activity in U.S. adolescents. Int J Behav Nutr Phys Act. 2010 in press.

Boone-Heinonen J, Gordon-Larsen P, Guilkey D, Jacobs DR, Popkin BM. Environment and physical activity dynamics: the role of residential self-selection. Psychology of Sport and Exercise. 2009 in press.

Boone JE, Gordon-Larsen P, Stewart JD, Popkin BM. Validation of a GIS facilities database: quantification and implications of error. Ann Epidemiol 2008;18:371-7. [PubMed: 18261922]

Chaix B, Merlo J, Evans D, Leal C, Havard S. Neighbourhoods in ecoepidemiologic research: delimiting personal exposure areas. A response to Riva, Gauvin, Apparicio and Brodeur. Soc Sci Med 2009;69:1306-10. [PubMed: 19692161]

Clarke P. When can group level clustering be ignored? Multilevel models versus single-level models with sparse data. J Epidemiol Community Health 2008;62:752-8. [PubMed: 18621963]

Colabianchi N, Dowda M, Pfeiffer KA, Porter DE, Almeida MJ, Pate RR. Towards an understanding of salient neighborhood boundaries: adolescent reports of an easy walking distance and convenient driving distance. Int J Behav Nutr Phys Act 2007;4:66. [PubMed: 18088416]

Diez-Roux AV, Nieto FJ, Muntaner C, Tyroler HA, Comstock GW, Shahar E, Cooper LS, Watson RL, Szklo M. Neighborhood environments and coronary heart disease: a multilevel analysis. Am J Epidemiol 1997;146:48-63. [PubMed: 9215223] 
Diez Roux AV. Neighborhoods and health: where are we and where do we go from here? Rev Epidemiol Sante Publique 2007;55:13-21. [PubMed: 17320330]

Diez Roux AV, Evenson KR, McGinn AP, Brown DG, Moore L, Brines S, Jacobs DR Jr. Availability of recreational resources and physical activity in adults. Am J Public Health 2007;97:493-9. [PubMed: 17267710]

Doyle SD, Kelly-Schwartz A, Schlossberg M, Stockard J. Active community environments and health. J Am Plan Assn 2006;72:19-31.

Ewing R, Schmid T, Killingsworth R, Zlot A, Raudenbush S. Relationship between urban sprawl and physical activity, obesity, and morbidity. Am J Health Promot 2003;18:47-57. [PubMed: 13677962]

Forsyth A, Hearst M, Oakes JM, Schmitz KH. Design and destinations: Factors influencing walking and total physical activity. Urban Studies 2008;45:1973-1996.

Frank LD, Andresen MA, Schmid TL. Obesity relationships with community design, physical activity, and time spent in cars. Am J Prev Med 2004;27:87-96. [PubMed: 15261894]

Frank LD, Kerr J, Sallis JF, Miles R, Chapman J. A hierarchy of sociodemographic and environmental correlates of walking and obesity. Prev Med. 2008

Giles-Corti B, Timperio A, Bull F, Pikora T. Understanding physical activity environmental correlates: increased specificity for ecological models. Exerc Sport Sci Rev 2005;33:175-81. [PubMed: 16239834]

Hernan MA, Hernandez-Diaz S, Robins JM. A structural approach to selection bias. Epidemiology 2004;15:615-25. [PubMed: 15308962]

Lovasi GS, Moudon AV, Smith NL, Lumley T, Larson EB, Sohn DW, Siscovick DS, Psaty BM. Evaluating options for measurement of neighborhood socioeconomic context: evidence from a myocardial infarction case-control study. Health Place 2008;14:453-67. [PubMed: 17950024]

McGarigal, K.; Cushman, SA.; Neel, MC.; Ene, E. FRAGSTATS: Spatial Pattern Analysis Program for Categorical Maps. University of Massachusetts; Amherst: 2002. Available at: www.umass.edu/landeco/research/fragstats/fragstats.html

Nelson MC, Gordon-Larsen P, Adair LS, Popkin BM. Adolescent physical activity and sedentary behavior: patterning and long-term maintenance. Am J Prev Med 2005;28:259-266. [PubMed: 15766613]

Oakes JM. The (mis)estimation of neighborhood effects: causal inference for a practicable social epidemiology. Soc Sci Med 2004;58:1929-52. [PubMed: 15020009]

Powell LM, Chaloupka FJ, Slater SJ, Johnston LD, O'Malley PM. The availability of local-area commercial physical activity-related facilities and physical activity among adolescents. Am J Prev Med 2007;33:S292-300. [PubMed: 17884577]

Resnick MD, Bearman PS, Blum RW, Bauman KE, Harris KM, Jones J, Tabor J, Beuhring T, Sieving RE, Shew M, Ireland M, Bearinger LH, Udry JR. Protecting adolescents from harm. Findings from the National Longitudinal Study on Adolescent Health. JAMA 1997;278:823-32. [PubMed: 9293990]

Roman CG, Chalfin A. Fear of walking outdoors. A multilevel ecologic analysis of crime and disorder. Am J Prev Med 2008;34:306-12. [PubMed: 18374244]

Saelens BE, Handy SL. Built environment correlates of walking: a review. Med Sci Sports Exerc 2008;40:S550-66. [PubMed: 18562973]

Saelens BE, Sallis JF, Frank LD. Environmental correlates of walking and cycling: findings from the transportation, urban design, and planning literatures. Ann Behav Med 2003;25:80-91. [PubMed: 12704009]

Soobader M, Cubbin C, Gee GC, Rosenbaum A, Laurenson J. Levels of analysis for the study of environmental health disparities. Environ Res 2006;102:172-80. [PubMed: 16781704]

Spielman SE, Yoo EH. The spatial dimensions of neighborhood effects. Soc Sci Med 2009;68:1098105. [PubMed: 19167802]

Vilhjalmsson R, Kristjansdottir G. Gender differences in physical activity in older children and adolescents: the central role of organized sport. Soc Sci Med 2003;56:363-74. [PubMed: 12473321] 
Vlahov D, Galea S. Urbanization, urbanicity, and health. Journal of Urban Health-Bulletin of the New York Academy of Medicine 2002;79:S1-S12. [PubMed: 12473694]

Wendel-Vos W, Droomers M, Kremers S, Brug J, van Lenthe F. Potential environmental determinants of physical activity in adults: a systematic review. Obes Rev 2007;8:425-40. [PubMed: 17716300]

Zhang, M.; Kukadia, N. Transportation and Land Development 2005. Transportation Research Board Natl Research Council; Washington: 2005. Metrics of urban form and the modifiable areal unit problem. 


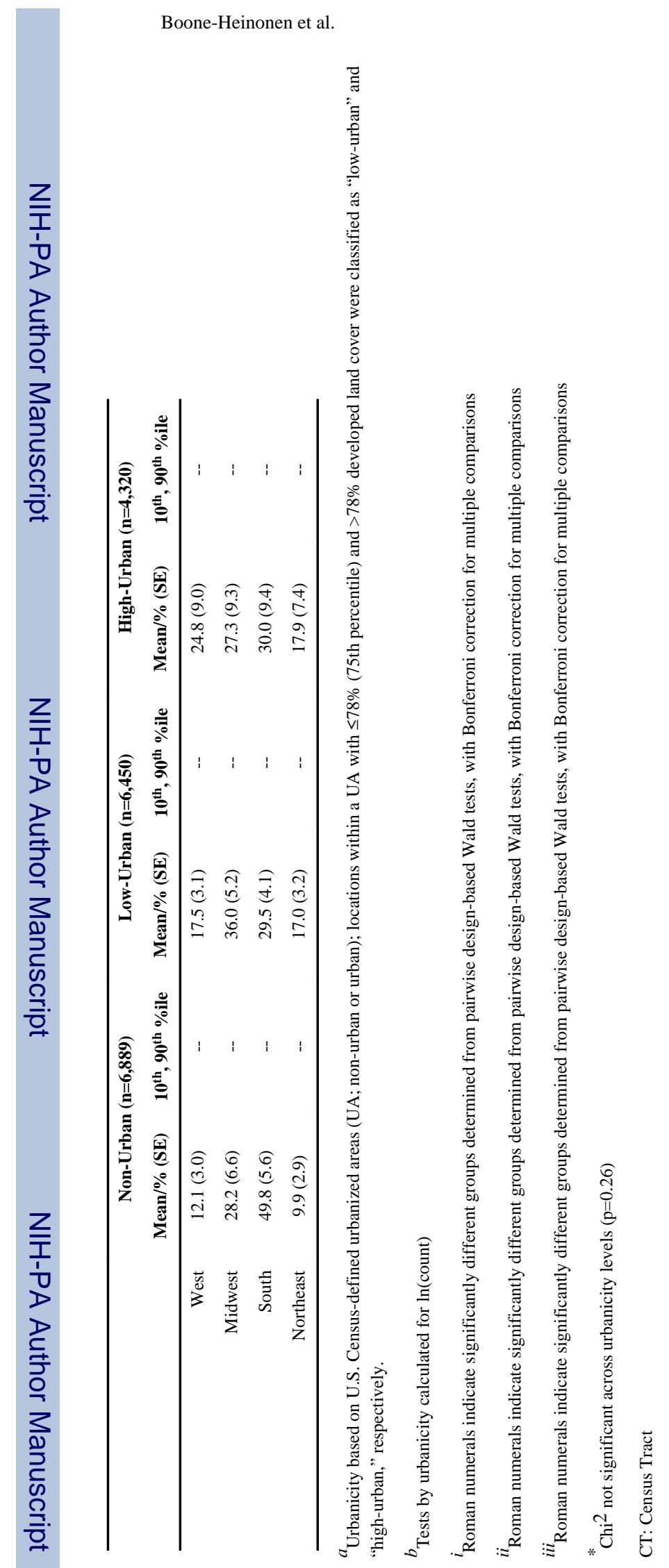

Health Place. Author manuscript; available in PMC 2011 November 1. 


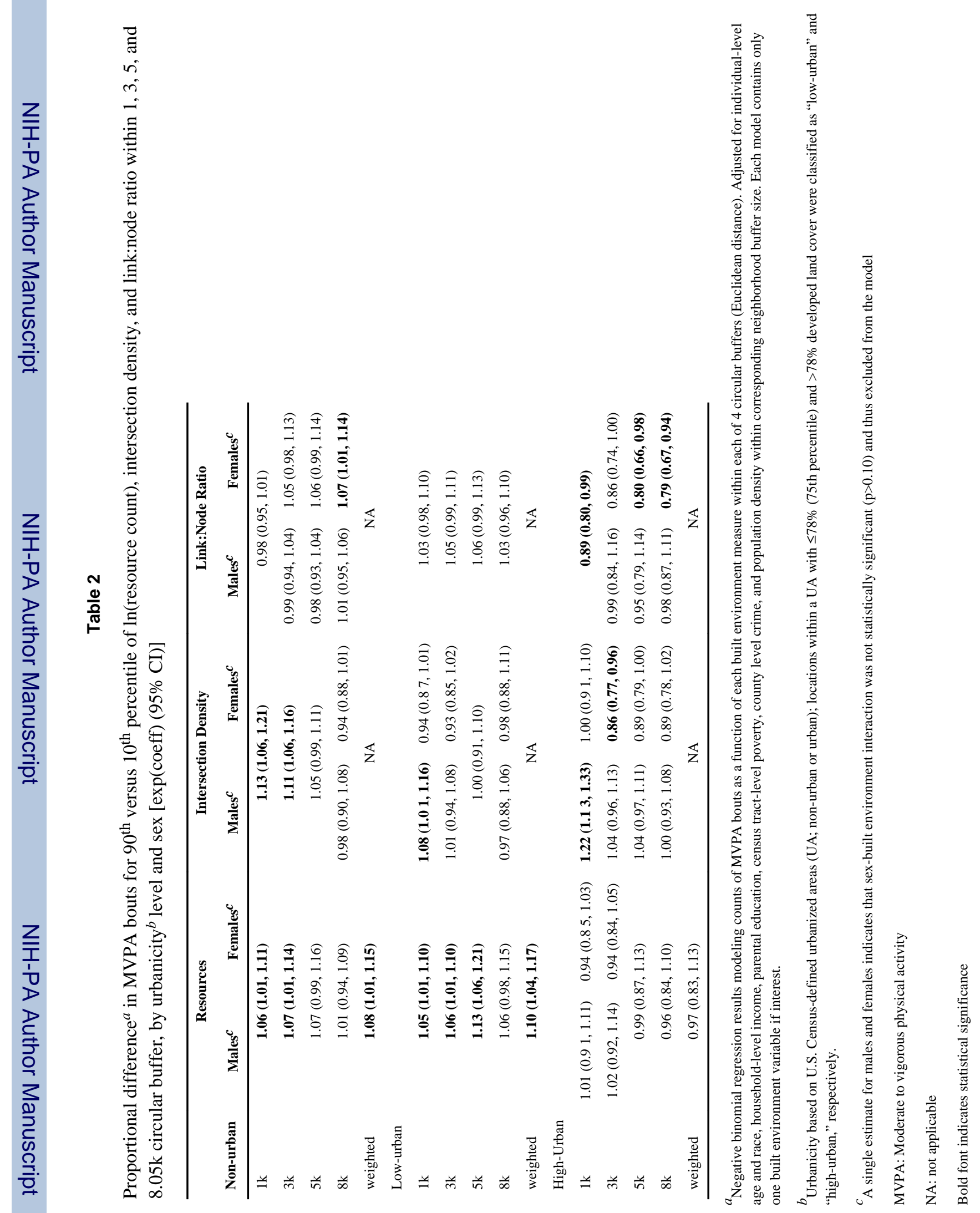


Table 3

Proportional difference ${ }^{a}$ in MVPA bouts for $90^{\text {th }}$ versus $10^{\text {th }}$ percentile of $\underline{\ln (\text { resource count) }}$ and connectivity combined, by urbanicity ${ }^{b}[\exp ($ coeff) $(95 \% \mathrm{CI})]$

\begin{tabular}{lcc}
\hline & Males $^{c}$ & Females $^{c}$ \\
\hline Non-urban & & \\
Resource count (weighted) & $1.00(0.94,1.05)$ \\
Intersection density (1k) & $\mathbf{1 . 1 4}(\mathbf{1 . 0 6 , 1 . 2 2})$ \\
Low-urban & \\
Resource count (weighted) & $\mathbf{1 . 0 7}(\mathbf{1 . 0 2}, \mathbf{1 . 1 3})$ \\
$\quad$ Intersection density (1k) & $1.06(0.98,1.14)$ & $0.92(0.85,1.00)$ \\
High-urban & & \\
Resource count (weighted) & $0.98(0.87,1.09)$ & $1.00(0.89,1.12)$ \\
Intersection density (1k) & $\mathbf{1 . 2 6}(\mathbf{1 . 1 4 , 1 . 3 8 )}$ & $1.01(0.90,1.12)$ \\
\hline
\end{tabular}

${ }^{a}$ Negative binomial regression results modeling MVPA bouts as a function of BE measure within each of 4 circular buffers. Adjusted for individual-level age and race, household-level income, parental education, census tract-level poverty, county level crime, and population density within $1 \mathrm{k}$

$b_{\text {Urbar }}$ >78\% developed land cover were classified as "low-urban" and "high-urban," respectively.

${ }^{c}$ A single estimate for males and females indicates that sex-built environment interaction was not statistically significant $(\mathrm{p}>0.10)$ and thus excluded from the model

MVPA, Moderate to vigorous physical activity

Bold font indicates statistical significance 